Communication

\title{
Performance Enhancement of DWDM-FSO Optical Fiber Communication Systems Based on Hybrid Modulation Techniques under Atmospheric Turbulence Channel
}

\author{
Mohammed R. Hayal ${ }^{1, *(\mathbb{D})}$, Bedir B. Yousif ${ }^{2,3}$ and Mohamed A. Azim ${ }^{1}$ \\ 1 Electronics and Communications Engineering Department, Faculty of Engineering, Mansoura University, \\ Mansoura 35516, El-Dakahlia Governorate, Egypt; mazim12@mans.edu.eg \\ 2 Electrical Engineering Department, Electronics and Communications Engineering Branch, \\ Faculty of Engineering, Kafrelsheikh University, Kafrelsheikh 33511, Kafrelsheikh Governorate, Egypt; \\ bedir.yousif@eng.kfs.edu.eg \\ 3 Electrical Engineering Department, Faculty of Engineering and Information Technology-Onaizah Colleges, \\ Ash Shabili 4403, Al-Qassim 56447, Saudi Arabia \\ * Correspondence: mohammedraisan@gmail.com
}

Citation: Hayal, M.R.; Yousif, B.B.; Azim, M.A. Performance Enhancement of DWDM-FSO Optical Fiber Communication Systems Based on Hybrid Modulation Techniques under Atmospheric Turbulence Channel. Photonics 2021, 8, 464. https://doi.org/10.3390/photonics8110464

Received: 26 August 2021

Accepted: 20 October 2021

Published: 22 October 2021

Publisher's Note: MDPI stays neutral with regard to jurisdictional claims in published maps and institutional affiliations.

Copyright: (c) 2021 by the authors. Licensee MDPI, Basel, Switzerland. This article is an open access article distributed under the terms and conditions of the Creative Commons Attribution (CC BY) license (https:// creativecommons.org/licenses/by/ $4.0 /)$.

\begin{abstract}
In this paper, we enhance the performance efficiency of the free-space optical (FSO) communication link using the hybrid on-off keying (OOK) modulation, M-ary digital pulse position modulation (M-ary DPPM), and M-pulse amplitude and position modulation (M-PAPM). This work analyzes and enhances the bit error rate (BER) performance of the moment generating function, modified Chernoff bound, and Gaussian approximation techniques. In the existence of both an amplified spontaneous emission (ASE) noise, atmospheric turbulence (AT) channels, and interchannel crosstalk (ICC), we propose a system model of the passive optical network (PON) wavelength division multiplexing (WDM) technique for a dense WDM (DWDM) based on the hybrid fiber FSO (HFFSO) link. We use eight wavelength channels that have been transmitted at a data rate of 2.5 Gbps over a turbulent HFFSO-DWDM system and PON-FSO optical fiber start from $1550 \mathrm{~nm}$ channel spacing in the C-band of $100 \mathrm{GHz}$. The results demonstrate $(2.5 \mathrm{Gbps} \times 8$ channels) $20 \mathrm{Gbit} / \mathrm{s}-4000 \mathrm{~m}$ transmission with favorable performance. In this design, M-ary DPPM-M-PAPM modulation is used to provide extra information bits to increase performance. We also propose to incorporate adaptive optics to mitigate the AT effect and improve the modulation efficiency. We investigate the impact of the turbulence effect on the proposed system performance based on OOK-M-ary PAPM-DPPM modulation as a function of M-ary DPPM-PAPM and other atmospheric parameters. The proposed M-ary hybrid DPPM-M-PAPM solution increases the receiver sensitivity compared to OOK, improves the reliability and achieves a lower power penalty of $0.2-3.0 \mathrm{~dB}$ at low coding level (M) 2 in the WDM-FSO systems for the weak turbulence. The OOK/M-ary hybrid DPPM-M-PAPM provides an optical signal-to-noise ratio of about 4-8 dB of the DWDM-HFFSO link for the strong turbulence at a target BER of $10^{-12}$. The numerical results indicate that the proposed design can be enhanced with the hybrid OOK/M-DPPM and M-PAPM for DWDM-HFFSO systems. The calculation results show that PAPM-DPPM has increased about $10-11 \mathrm{~dB}$ at BER of $10^{-12}$ more than the OOK-NRZ approach. The simulation results show that the proposed hybrid optical modulation technique can be used in the DWDM-FSO hybrid links for optical-wireless and fiber-optic communication systems, significantly increasing their efficiency. Finally, the use of the hybrid OOK/M-ary DPPM-M-PAPM modulation schemes is a new technique to reduce the AT, ICC, ASE noise for the DWDM-FSO optical fiber communication systems.
\end{abstract}

Keywords: ASE noise; ICC; DWDM-FSO/PON optical fiber network; hybrid OOK/M-ary DPPM-MPAPM; hybrid fiber FSO (HFFSO) link 


\section{Introduction}

Pulse position modulation (PPM) and digital PPM (DPPM) and systems are modulation schemes that can perform great performance in free-space optical (FSO) transmission links [1,2]. This format is used in a variety of applications, including FSO links, hybrid fibers, optical wireless communication (OWC), subsequent FSO systems, satelliteto-satellite systems, atmospheric turbulence (AT), interchannel crosstalk (ICC), and indoor wireless channels [1-3]. The modulation of DPPM improves power efficiency and does not require monitoring of decision-making circuit thresholds [4,5]. Many experiments on the hybrid fiber/FSO (HFFSO) systems and the OWC have been carried out [5-9]. Previous researches have demonstrated that the DPPM and PPM schemes outperform on-off keying (OOK) in terms of sensitivity and power efficiency for the HFFSO link. The M-pulse amplitude and position modulation (M-PAPM) for both pulse amplitude modulation (PAM) and PPM modulation have been investigated and studied for optical fiber (OF) communications [5-8]. M-PAPM can provide high efficiency and sensitivity in the FSO communication; because the dispersion is free $[1,5,8]$. Because of the increased bandwidth requirement for higher data rates, OF, AT, OWC and indoor networks [8-15] have been proposed to multiplex the wavelength division multiplexing (WDM) technique and dense WDM (DWDM) systems. The WDM technique could also be used in the HFFSO, OWC, and hybrid OF/multiple networks. For example, the proposed approach designs a high-performance system and bandwidth optimization solution with long-range potential, higher bit rates, high-speed technology, and enhanced data protection for WDM passive optical networks (WDM-PON) $[8,9,13,16]$. The WDM application has been presented in both OF and FSO systems [8,9,17-21]. A suitable technique for representing amplified spontaneous emission noise (ASE) in an FSO transmission link is the moment generating function (MGF), although we have upper limits at the bit-error-rate (BER) using the updated techniques of Chernoff bound (CB), Gaussian approximating (GA), and modified Chernoff bound (MCB) $[5,8,9,22-25]$. Both the FSO and OF systems have been presented using WDM technology [8,9,17-21]. The moment generating function (MGF) represents a suitable technique for finding the amplified spontaneous emission (ASE) noise in an FSO transmission link $[2,9,17]$. Using the modified Chernoff bound (MCB) technique, Gaussian approximations (GA), and Chernoff bound (CB), we obtain upper bounds on the bit error rate (BER) $[5,8,9,21-25]$. To reduce the AT impact, approaches are proposed including compensation for the mitigation techniques and adaptive optics (AO) focused on digital signal processing [22]. We highlight the main contributions, including: (1) we use the M-ary DPPM-M-PAPM modulation to deliver additional bits to improve the efficiency; (2) we add the AO to minimize the ICC interferences and enhance the reliability performances; (3) we achieve adequate BER results with a lower complexity; (4) we extract the theoretical BER expressions and provide simulation results for M-DPPM-M-PAPM modulation schemes in the WDM-PON/HFFSO scenarios; (5) the hybrid OOK/M-ary DPPM-M-n-PAPM and the $\mathrm{AO}$ are offered to boost the performance and system efficiency in receivers of WDM-HFFSO systems through the OOK non-return-to-zero (OOK-NRZ) modulation; and (6) we improve the power penalty (PP) performance and the system efficiency for the WDM-HFFSO systems, optical-wireless and fiber-optic communication systems. In this work, we enhance the hybrid OOK/DPPM-M-PAPM techniques and improve the signal-to-noise-ratios (SNRs) of the HFFSO systems under the AT effects, ICC, and ASE. In this work, we enhance the hybrid OOK/DPPM-M-PAPM systems and improve the signal-to-noise-ratios (SNRs) of the HFFSO under the AT, ICC, and ASE effects. We develop the proposed model in the $[9,17]$. Also, we enhance our calculations and evaluate them to reduce the AT, and ASE noise. The remainder of the paper is organized as follows: Section 2 describes the proposed PON/WDM-HFFSO optical fiber communication system. Section 3 discusses the M-ary DPPM-M-PAPM model for the hybrid WDM-PON/HFFSO link. The AT channel effects are analyzed in Section 4. The numerical results are presented in Section 5. Section 6 concludes this paper. 


\section{System Description}

The length of slots $t_{s}=M_{b} / n$ is for the DPPM frames, $n=2^{M}$ where $T_{b}=1 / R_{b}$ is for the bit cycle, $R_{b}$ for the data rate and $M$ is for the coding level (CL) [9]. Figure 1a shows the HFFSO-PON systems where optical signals (OSs) suffer from the ASE noise (ASEN), beam-spreading, beam-absorption, attenuation, ICC, and splitting losses at the optical band-pass filter (OBPF)/demux. The proposed system is modeled and simulated using MATLAB software (2013). The results are based on Monte-Carlo simulations. We use eight channels WDM-DWDM starting from $1550 \mathrm{~nm}$ over single-mode fiber and the channel spacing in the C-band of $100 \mathrm{GHz}$ of the ITU (International Telecommunication Union). The results demonstrate $(2.5 \mathrm{Gbps}$ data rate $\times 8$ channels $) 20 \mathrm{Gbit} / \mathrm{s}-4000 \mathrm{~m}$ transmission with favorable performance. We investigate eight-wavelength channels that have been transmitted over turbulent HFFSO links using the WDM technique. The feeder fiber path length of $20 \mathrm{~km}$ is proposed for the system model $[8,15,17]$. By using the optical amplifier (OA) gain $\mathrm{G}$ on the remote node, we improve the device model after receiver collection lens (RCL) as seen in Figure 1a. We propose that the OA system is used to reduce the interchannel crosstalk for the proposed system. Figure $1 \mathrm{~b}$ shows the proposed architecture for all scenarios [9]. As seen in Figure 1, M-ary DPPM is transmitted over the OA and OBPF (b). The receiver converts the OS into an electrical signal. The module of the receivers consists of a photodetector (PD), an electric amplifier, a filter, and a compared circuitry for the decision circuit and AO. We propose the hybrid pulse modulation/M-ary DPPM-M-PAPM for the DWDM-FSO and hybrid optical fiber over the atmospheric turbulence channel. Information is transmitted as a series of DPPM-M-PAPM pulses. The modulated signal from M-ary DPPM-M-PAPM is connected to OA and OBPF to provide M-ary DPPM-MPAPM output as shown in Figure 1b [9]. For our calculations, we assume the loss of the signal multiplexer (mux)/demultiplexer (demux) $(\leq 3.5 \mathrm{~dB})[8,15]$.

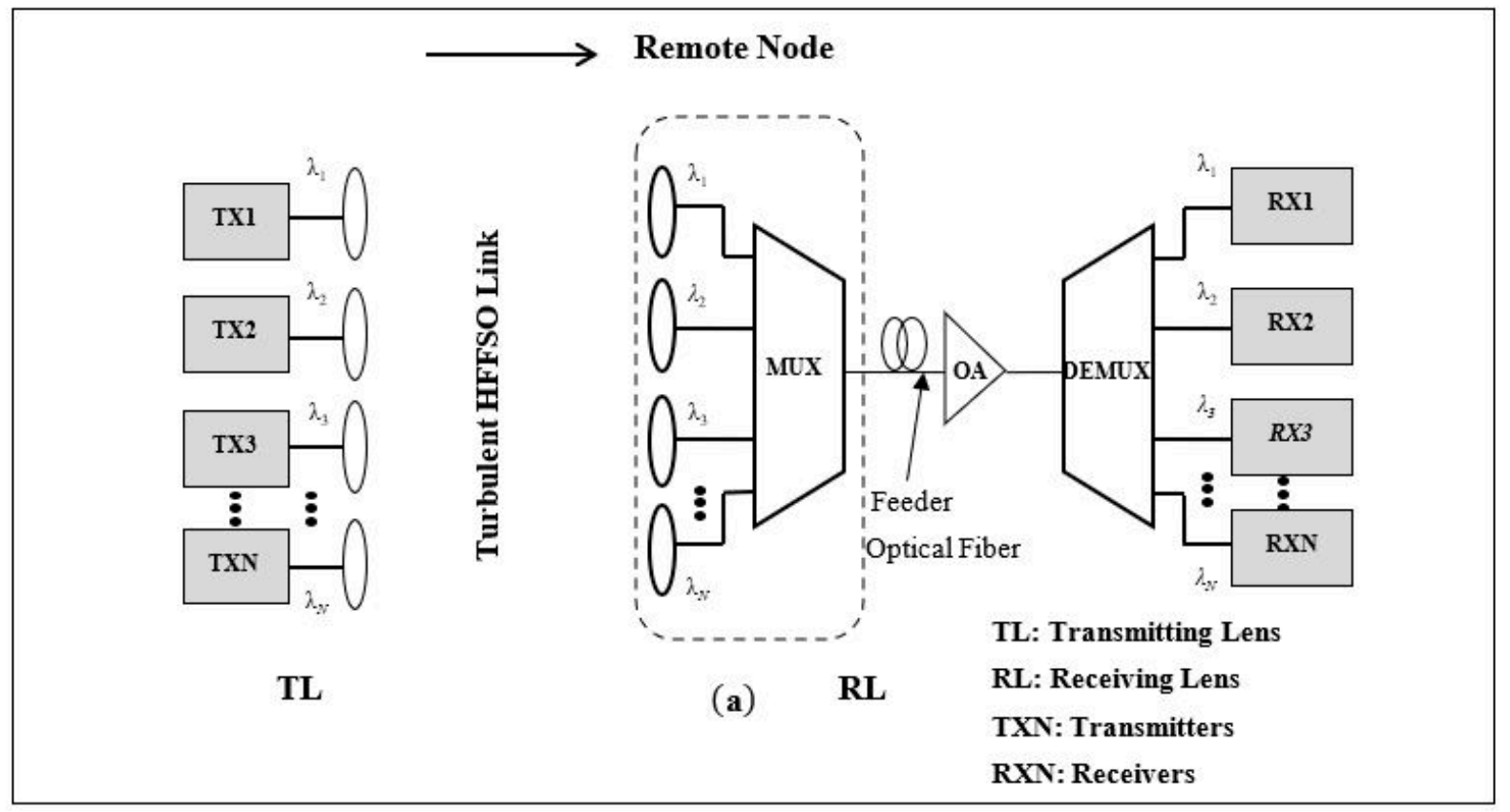

Figure 1. Cont. 


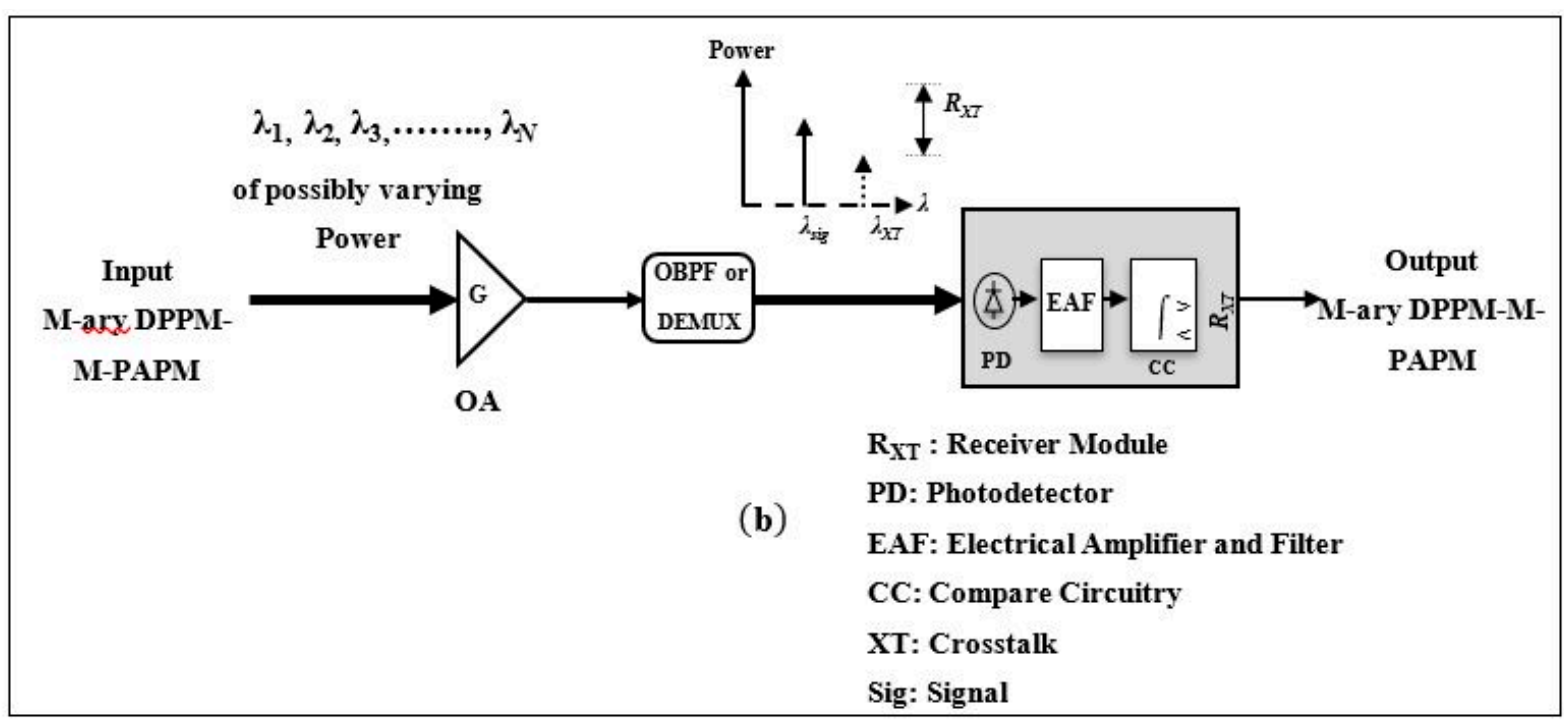

Figure 1. System model for 8 channels PON-DWDM-HFFSO for OOK-NRZ/M-ary DPPM-M-PAPM under moderate turbulence (MT), strong turbulence (ST), and weak turbulence (WT): (a) proposed framework for interchannel crosstalk (ICC) evaluation and (b) schematic of the receiver system. We reproduced it from [9].

\section{M-ary Digital Pulse Position Modulation and M-pulse Amplitude and Position Modulation (M-ary DPPM-M-PAPM) Scheme}

In this section, the random variable (RV) of the MGF describes the current $Y_{\text {sig }}(\Delta t)$ where sig $\in\{0,1\}$ which depends on the pulses or is not transmitted for the signal pulses, $\Delta t$ is the duration of the crosstalk pulse. It is written as $[5,9,24,26-28]$ :

$$
\mathrm{M}_{\mathrm{Y}_{\mathrm{sig}}(\Delta \mathrm{t})}(\mathrm{s})=\left\{\frac{R^{\prime} \mathrm{G}\left(\mathrm{e}^{\mathrm{sq} / \mathrm{t}_{\mathrm{s}}}-1\right) \int_{\mathrm{t}_{\mathrm{s}}} \operatorname{sig} P_{\mathrm{tr}}(\mathrm{t}) \mathrm{dt}}{1-R^{\prime} N_{o}\left(\mathrm{e}^{\mathrm{sq} / \mathrm{t}}-1\right)}\right\} \frac{\exp \left\{\frac{R_{\mathrm{i}}^{\prime} \mathrm{G}\left(\mathrm{e}^{\mathrm{sq} / \mathrm{ts}_{\mathrm{s}}}-1\right) \int_{\Delta \mathrm{t}} \mathrm{P}_{\mathrm{TT}}(\mathrm{t}) \mathrm{dt}}{1-R_{\mathrm{i}}^{\prime} \mathrm{N}_{o_{-} \mathrm{XT}}\left(\mathrm{e}^{\mathrm{sq} / \mathrm{ts}_{\mathrm{s}}}\right)}\right\}}{\left[1-R^{\prime} N_{o}\left(\mathrm{e}^{\mathrm{sq} / \mathrm{t}_{\mathrm{s}}}-1\right)\right]^{\mathrm{L}}}
$$

where $\Delta t=t_{s}$ is the time slots align with the OS slots otherwise $t_{1}$ or $t_{2}$, and $\Delta t=0$ for no crosstalk in the slot. Furthermore, the DPPM-PAPM pulse and ICC pulse strength are $P_{t r}$, $\mathrm{P}_{\mathrm{XT}}$, respectively for the hybrid modulation techniques over the FSO link. $R^{\prime}=\eta / h v_{i}, \eta$ is the PD quantum efficiency, $v_{i}, v$ and are the optical frequencies of ICC wavelengths and signal respectively and $h$ is Planck's constant, q is the electron charge, [5,8-10,29-34], $N_{o}=0.5(\mathrm{NF} \times \mathrm{G}-1) h v$ is the OA power spectral density (PSD) at the single polarization ASEN. NF and G are the noise figure and OA gain G respectively, $L=B_{o} m_{t} t_{s}$ encompass the system modes for the spatial and temporal method [2,8,9,35-42], $B_{0}$ is the bandwidth of the optical noise for the demux channel and $m_{t}$ is the number of ASEN states. $N_{o_{-} \mathrm{XT}}$ is the PSD-ASEN at the PD and the signal-to-crosstalk ratio $\mathrm{C}_{\mathrm{XT}}=\mathrm{P}_{\mathrm{tr}} / \mathrm{P}_{\mathrm{XT}}$. The total MGF for Gaussian zero-mean, including the thermal noise variance (TNV) is calculated as $[5,9,35-42]$ :

$$
\mathrm{M}_{\mathrm{Y}_{\mathrm{sig}}(\Delta \mathrm{t})}(\mathrm{s})=\mathrm{M}_{\mathrm{Y}_{\mathrm{sig}}(\Delta \mathrm{t})}(\mathrm{s}) \exp \left(\frac{\mathrm{s}^{2} \sigma_{\mathrm{th}}^{2}-\mathrm{DPPM}-\mathrm{PAPM}}{2}\right)
$$

where $\sigma_{\text {th-DPPM }}^{2}$ is the DPPM-PAPM TNV. The means and variances are given as [5,9]:

$$
\mu_{\mathrm{Y}_{\mathrm{sig}}(\Delta \mathrm{t})}(s)=\frac{L R^{\prime} q N_{o}}{t_{s}}+R^{\prime} G q\left(\operatorname{sig} \mathrm{P}_{\mathrm{tr}} \frac{\mathrm{P}_{\mathrm{XT}} \Delta \mathrm{t}}{t_{s}}\right)
$$

$$
\sigma_{\mathrm{X}_{\mathrm{sig}}(\Delta \mathrm{t})}^{2}=\sigma_{\mathrm{th}-\mathrm{DPPM}-\mathrm{PAPM}}^{2}+\left(\frac{L R^{\prime} q^{2} N_{o}\left(1+R^{\prime} N_{o}\right)}{t_{S}^{2}}\right)+R^{\prime} G q^{2}\left[\left(1+2 R^{\prime} N_{o}\right) \frac{\operatorname{sigP}}{t_{\mathrm{tr}}}\right]+R_{i}^{\prime} G q^{2}\left[\left(1+2 \mathrm{R}_{\mathrm{i}}^{\prime} N_{o \mathrm{XT}}\right) \frac{\mathrm{P}_{\mathrm{XT}} \Delta \mathrm{t}}{t_{s}^{2}}\right]
$$


The symbol error probability (SER) is received in the exist of ICC $\mathrm{P}_{\mathrm{ws}\left(\mathrm{I}_{\mathrm{i}}-\mathrm{r}_{\mathrm{i}}\right)}$ :

$$
P_{w s\left(I_{i}-r_{i}\right)} \geq \prod_{\substack{j=1 \\ j \neq \text { sigslot }}}^{n} P\left(X_{1}(\Delta t)>X_{j}\right)
$$

where $X_{j}$ denotes the non-signal slot $X_{o}\left(\Delta t_{j}\right)$ and $\Delta t_{j}$ is the $j$ (empty) slot overlap with the ICC. Using the GA, the expression $P\left\{X_{o}\left(\Delta t_{j}\right)>X_{1}(\Delta t)\right\}$ is explained from $[1,2,5,9,10,29]$ :

$$
\mathrm{P}\left\{\mathrm{X}_{\mathrm{o}}\left(\Delta \mathrm{t}_{\mathrm{j}}\right)>\mathrm{X}_{1}(\Delta \mathrm{t})\right\}=0.5 \operatorname{erfc}\left(\frac{\mu_{\mathrm{X}_{1}(\Delta \mathrm{t})}-\mu_{\mathrm{X}_{0}\left(\Delta \mathrm{t}_{\mathrm{j}}\right)}}{\sqrt{2\left(\sigma_{\mathrm{X}_{1}(\Delta \mathrm{t})}^{2}+\sigma_{\mathrm{X}_{0}\left(\Delta \mathrm{t}_{\mathrm{j}}\right)}^{2}\right)}}\right)
$$

In the proposed $C B$, we have fixed threshold $T_{\text {th }}$ and the general form for $R V(X)$ variable and $\mathrm{a}$ is $\mathrm{P}\left(\mathrm{X}>\mathrm{T}_{\text {th }}\right) \leq \mathrm{E}\left\{\exp \left[\mathrm{s}\left(\mathrm{X}-\mathrm{T}_{\text {th }}\right)\right]\right\}, \mathrm{s}>0$ :

$$
\mathrm{P}\left\{\mathrm{X}_{\mathrm{o}}\left(\Delta \mathrm{t}_{\mathrm{j}}\right)>\mathrm{X}_{1}(\Delta \mathrm{t})\right\} \leq \mathrm{M}_{\mathrm{X}_{1}(\Delta \mathrm{t})}(-\mathrm{s}) \mathrm{M}_{\mathrm{X}_{0}(\Delta \mathrm{t})}(\mathrm{s})(\mathrm{s}>0)
$$

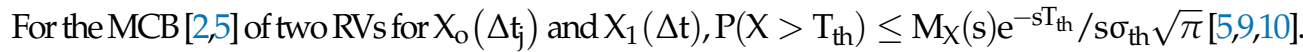
Modifying this inequality for the diffe rence of RVs s for $\mathrm{X}_{\mathrm{o}}\left(\Delta \mathrm{t}_{\mathrm{j}}\right)$ and $\mathrm{X}_{1}(\Delta \mathrm{t})$ which both have the same TNV then:

$$
\mathrm{P}\left\{\mathrm{X}_{\mathrm{o}}\left(\Delta \mathrm{t}_{\mathrm{j}}\right)>\mathrm{X}_{1}(\Delta \mathrm{t})\right\} \leq \frac{\mathrm{M}_{\mathrm{X}_{1}(\Delta \mathrm{t})}(-\mathrm{s}) \mathrm{M}_{\mathrm{X}_{0}(\Delta \mathrm{t})}(\mathrm{s})}{2 \mathrm{~s} \sigma_{\mathrm{th}} \sqrt{\pi}}(\mathrm{s}>0)
$$

The SER for MDPPM-MPAPM frames in the exist of ICC is written as $[1,9,10]$ :

$$
\mathrm{P}_{\mathrm{we}\left(\mathrm{I}_{\mathrm{s}}-\mathrm{r}_{\mathrm{s}}\right)} \leq 1-\left[1-\mathrm{P}\left\{\mathrm{X}_{\mathrm{o}}(0)>\mathrm{X}_{1}(\Delta \mathrm{t})\right\}\right]^{\mathrm{n}-1\left(\mathrm{I}_{\mathrm{s}}-\mathrm{r}_{\mathrm{s}}\right)}\left[1-\mathrm{P}\left\{\mathrm{X}_{\mathrm{o}}\left(\mathrm{t}_{\mathrm{s}}\right)>\mathrm{X}_{1}(\Delta \mathrm{t})\right\}\right]^{\mathrm{I}_{\mathrm{s}}-\mathrm{r}_{\mathrm{s}}}
$$

where and $I_{s}, r_{s}$ are the numbers of ICC system of duration $t_{s}$ occurring in the frame and signal pulse respectively [42],

$$
\mathrm{P}_{\text {we }\left(\mathrm{I}_{1}, \mathrm{I}_{2}-\mathrm{r}_{1}, \mathrm{r}_{2}\right)} \leq 1-\left[1-\mathrm{P}\left\{\mathrm{X}_{\mathrm{o}}(0)>\mathrm{X}_{1}(\Delta \mathrm{t})\right\}\right]^{\mathrm{n}-1-\ddot{\chi}}\left[1-\mathrm{P}\left\{\mathrm{X}_{\mathrm{o}}\left(\mathrm{t}_{1}\right)>\mathrm{X}_{1}(\Delta \mathrm{t})\right\}\right]^{\mathrm{I}_{1}-\mathrm{r}_{1}}\left[1-\mathrm{P}\left\{\mathrm{X}_{\mathrm{o}}\left(\mathrm{t}_{2}\right)>\mathrm{X}_{1}(\Delta \mathrm{t})\right\}\right]^{\mathrm{I}_{2}-\mathrm{r}_{2}}
$$

where $\mathrm{I}_{1}, \mathrm{I}_{2}$, and $\mathrm{r}_{1}, \mathrm{r}_{2}$ are the ICC duration $\mathrm{t}_{1}, \mathrm{t}_{2} \cdot \ddot{\chi}=\mathrm{I}_{\mathrm{s}}-\mathrm{r}_{\mathrm{s}}$. The BER when without ICC is written as:

$$
\begin{gathered}
\operatorname{BER}_{\mathrm{I}_{\mathrm{S}}}\left(n_{1}\right)=\mathrm{p}_{\mathrm{f}\left(\mathrm{I}_{\mathrm{S}}\right)}\left(n_{1}\right)=\frac{n}{2(n-1)} \times\left(\mathrm{p}_{\mathrm{f}\left(\mathrm{I}_{\mathrm{s}}\right)}(1) \mathrm{P}_{\mathrm{we}\left(\mathrm{I}_{\mathrm{s}}-1\right)}+\mathrm{p}_{\mathrm{s}\left(\mathrm{I}_{\mathrm{S}}\right)}(0) \mathrm{P}_{\mathrm{we}\left(\mathrm{I}_{\mathrm{s}}-0\right)}\right) \\
\operatorname{BER}=\frac{1}{n} \sum_{n_{1}=1}^{n} \sum_{\mathrm{I}_{\mathrm{s}}=0}^{2} \operatorname{BER}_{\mathrm{I}_{\mathrm{S}}}\left(n_{1}\right) \\
\operatorname{BER}\left(n_{1}\right)=\mathrm{p}_{\mathrm{f}(0,0)}\left(n_{1}\right) \frac{n}{2(n-1)} \mathrm{P}_{\mathrm{we}\left(0,0 \_0,0\right)}
\end{gathered}
$$

while for the calculated BER, we have written as $[1,2,29,35-42]$ :

$$
\begin{aligned}
& \operatorname{BER}_{\mathrm{I}_{1}, \mathrm{I}_{2}}\left(n_{1}\right)=\frac{1}{n} \sum_{\mathrm{t}_{1}=\mathrm{t}_{\mathrm{c}}}^{\mathrm{t}_{\mathrm{s}}} \mathrm{p}_{\mathrm{f}\left(\mathrm{I}_{1}, \mathrm{I}_{2}\right)}\left(n_{1}\right) \frac{n}{2(n-1)}\left\{\begin{array}{c}
{\left[\mathrm{p}_{\mathrm{s}\left(\mathrm{I}_{1}, \mathrm{I}_{2}\right)}(1,0) \mathrm{P}_{\left.\mathrm{we}\left(\mathrm{I}_{1}, \mathrm{I}_{21,0}\right)\right]}\right.} \\
+\left[\mathrm{p}_{\mathrm{s}\left(\mathrm{I}_{1}, \mathrm{I}_{2}\right)}(0,1) \mathrm{P}_{\mathrm{we}\left(\mathrm{I}_{1}, \mathrm{I}_{20,1}\right)}\right]
\end{array}\right\} \\
& +\mathrm{p}_{\mathrm{s}\left(\mathrm{I}_{1}, \mathrm{I}_{2}\right)}(0,0) \mathrm{P}_{\mathrm{we}\left(\mathrm{I}_{1}, \mathrm{I}_{20,0}\right)}
\end{aligned}
$$


In the presence of ICC, the overall BER of the M-DPPM-M-PAPM is calculated from Equations (13) and (14) [1,2,29]:

$$
\mathrm{BER}_{\mathrm{M}-\mathrm{DPPM}-\mathrm{M}-\mathrm{PAPM}}=\frac{1}{n} \sum_{n_{1}=1}^{n}\left\{\begin{array}{c}
\operatorname{BER}\left(n_{1}\right)+\mathrm{BER}_{0,1}\left(n_{1}\right)+\mathrm{BER}_{1,0}\left(n_{1}\right) \\
+\sum_{\mathrm{I}_{1}=1}^{2}\left[\operatorname{BER}_{\mathrm{I}_{1}, 1}\left(n_{1}\right)+\operatorname{BER}_{\mathrm{I}_{1}, 2}\left(n_{1}\right)\right]
\end{array}\right\}
$$

\section{Atmospheric Turbulence Channel}

Differences in the air and variation between the refractive index structure (RIS) $C_{n}^{2}$ and Earth's surface temperature are responsible for the scintillation effects [8]. These findings are focused on the probability density function (pdf) of the Gamma-Gamma (GG) model [5,8,9,29-34].

$$
p_{\mathrm{GG}}\left(h_{Z}\right)=\frac{2(\alpha \beta)^{(\alpha+\beta) / 2}}{\Gamma(\alpha) \Gamma(\beta)} h_{Z}^{((\alpha+\beta) / 2)-1} K_{\alpha-\beta}\left(2 \sqrt{\alpha \beta h_{Z}}\right) ; h_{Z}>0
$$

where $h_{Z}$ is the total attenuations due to the signal $\left(\mathrm{h}_{\text {sig }}\right)$ and interfering $\left(\mathrm{h}_{\mathrm{int}}\right)$ and pointing errors. $\alpha$ and $\beta$ are the scattering methods of the influence of the large and small-eddies, respectively, and $\Gamma(\cdot)$ is the gamma function, and $\mathrm{K}_{\mathrm{n}}(\cdot)$ is the modified second kind Bessel function $[8,10]$.

$$
\begin{gathered}
\alpha=\left\{\exp \left[\frac{0.49 \sigma_{R}^{2}}{\left(1+0.65 d^{2}+1.11 \sigma_{R}^{12 / 5}\right)^{7 / 6}}\right]-1\right\}^{-1} \\
\beta=\left\{\exp \left[\frac{0.51 \sigma_{R}^{2}\left(1+0.69 \sigma_{R}^{12 / 5}\right)^{-5 / 6}}{1+0.9 d^{2}+0.62 d^{2} \sigma_{R}^{12 / 5}}\right]-1\right\}^{-1} \\
\mathrm{~d}=\sqrt{\mathrm{kD}_{\mathrm{RX}}^{2} / 4 l_{f s o}}
\end{gathered}
$$

where $d$ is the normalized RCLs $[8-10,30,33]$ and $D_{R X}$ is the RCL diameter. $C_{n}^{2}$ is the RIS constant, $l_{f s o}$ is the free-space distance, $k=2 \pi / \lambda$ is the wave-number, and $\lambda$ is the wavelength $[29,30,34-40]$. The Rytov variance (RVAR) $\sigma_{R}^{2}$ characterize the different AT regimes over the GG pdf, if the resulting $\sigma_{R}^{2}>1$; we use the ST, if the RVAR $\sigma_{R}^{2} \approx 1$, we use the MT, if RVAR $\sigma_{\mathrm{R}}^{2}<1$, we apply the WT [8-10,29]; and if saturated, turbulence $\sigma_{\mathrm{R}}^{2} \rightarrow \infty$ are given as in $[8-10,40-46]$ :

$$
\sigma_{\mathrm{R}}^{2}=1.23 \mathrm{C}_{\mathrm{n}}^{2} \mathrm{k}^{7 / 6} l_{f s o}^{11 / 6}
$$

\section{Results and Discussion}

Table 1 shows the proposed parameters for the system model [proposed values] and values in Refs. $[2,17,42]$ used in the system architecture. The proposed design parameters are specified in Table 1 [proposed] and [2,17,42]. We investigate the impact of the turbulence effect on the proposed system performance based on the OOK-M ary-DPPM modulation as a function of M-ary DPPM-PAPM and other atmospheric parameters. Figure 2 shows the high gain $(G=30 \mathrm{~dB})$ of the AT impact in the case of BER. MCB and $C B$ are about the same, through AT strength rises [9,10,43-46]. The curves of $C B$ and MCB vary from GA. The high (a) $(\mathrm{G})=27 \mathrm{~dB}$ [42] and $\mathrm{G}=30 \mathrm{~dB}$ [current work] with the ICC is shown in Figure 3. For $M=2$ and (b) $G=8 d B$, the present work shows the $M C B, C B$, and $G A$ output. The MCB synchronizes with the GA on low $G$ in Figure 3a but at high $G$ is near the $\mathrm{CB}$ with as the ASEN decreases the TNV results. The GA at high G with no ICC and in the existence of ICC exceeds the CB and MCB. The CB extends the CL and bandwidth of the DPPM-PAPM receiver for noise equivalent $B_{e}$. The margin of the GA is greater than the MCB of the PAPM-M-DPPM. The MCB, CB, and GA output of a $G=8 \mathrm{~dB}$ with an ICC 
and $M=2$ is shown in Figure $3 b$. The results are enhanced and validated with Ref. [42]. The MCB synchronizes with the GA at low $G$ but gains considerably near the $\mathrm{CB}$ as the ASEN reduces the TNV impacts [43-46].

Table 1. System parameters used for calculations in $[2,17,42]$ and [Proposed work].

\begin{tabular}{|c|c|c|c|c|}
\hline Parameters & Description & Refs. [2,17] & Ref. [42] & [Proposed Work] \\
\hline$R_{b}$ & Data rate & $2.5 \mathrm{Gbps}$ & $2.5 \mathrm{Gbps}$ & $2.5 \mathrm{Gbps}$ \\
\hline$B_{o}$ & $\begin{array}{l}\text { Demux OBPF } \\
\text { bandwidth }\end{array}$ & $80 \mathrm{GHz}$ & $76 \mathrm{GHz}$ & $80 \mathrm{GHz}$ \\
\hline$\lambda_{\text {sig }}$ & Wavelength & $1550 \mathrm{~nm}$ & $1550 \mathrm{~nm}$ & $1550 \mathrm{~nm}$ \\
\hline$\eta$ & $\begin{array}{l}\text { Quantum } \\
\text { efficiency }\end{array}$ & 0.75 & 0.9 & 1 \\
\hline G & OA gain & $30.6 \mathrm{~dB}$ or $8.8 \mathrm{~dB}$ & $27 \mathrm{~dB}$ or $8 \mathrm{~dB}$ & $30 \mathrm{~dB}$ or $8 \mathrm{~dB}$ \\
\hline NF & OA noise figure & $4.77 \mathrm{~dB}[2]$ & $4.77 \mathrm{~dB}[2]$ & $4.77 \mathrm{~dB}[2]$ \\
\hline$l_{f s o}$ & $\begin{array}{l}\text { FSO link length } \\
\text { ASE noise }\end{array}$ & $1000 \mathrm{~m}$ and $1500 \mathrm{~m}$ & $1000 \mathrm{~m}$ and $1500 \mathrm{~m}$ & $1500 \mathrm{~m}$ and $4000 \mathrm{~m}$ \\
\hline$m_{t}$ & $\begin{array}{c}\text { polarization } \\
\text { states }\end{array}$ & 2 & 2 & 2 \\
\hline
\end{tabular}

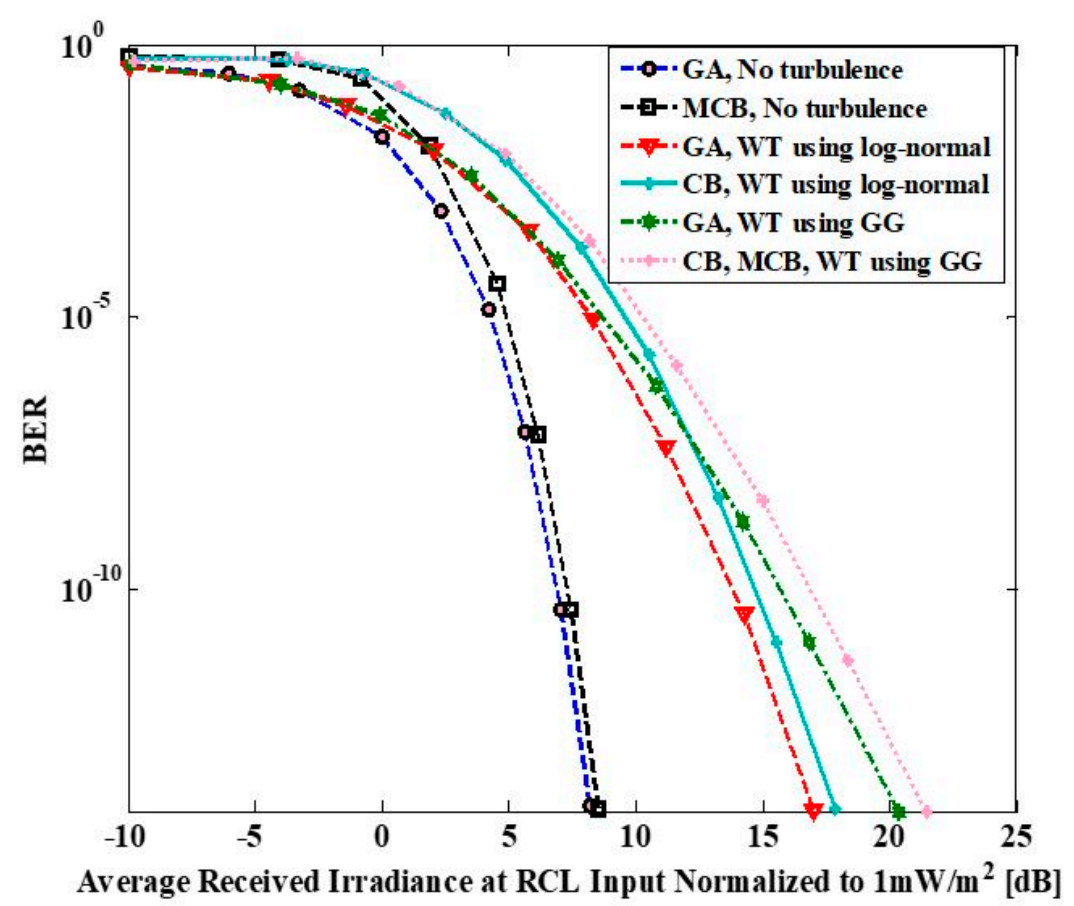

Figure 2. The bit error rate (BER) against an average irradiance $[\mathrm{dB}]$ for no turbulence (NT), and WT using Gamma-Gamma (GG) model and log-normal distribution.

In the case of BER targets of $10^{-12}$, ST and WT using MCB, CB, and GA, the receiver sensitivity (RS) is applied for $\mathrm{G}=30.6 \mathrm{~dB}$ and $l_{f s o}=1500 \mathrm{~m}[2,9,40]$ as shown in Figure $4 \mathrm{a}, \mathrm{b}$. Numerical results demonstrated that RSs are $-51.49 \mathrm{dBm}(\mathrm{CB}),-51.59 \mathrm{dBm}(\mathrm{MCB})$, and $50.53 \mathrm{dBm}(\mathrm{GA})$, resulting in improvement and optimization as achieved in $[2,9,40]$. The RS of $-51.49 \mathrm{dBm}(\mathrm{CB}),-51.56 \mathrm{~dB}(\mathrm{MCB})$, and $-50.25 \mathrm{dBm}(\mathrm{GA})$ is presented for $\mathrm{G}=30 \mathrm{~dB}$, $l_{f s o}=2500 \mathrm{~m}$, at target BER of $10^{-12}$ [Proposed work]. Figure 5 shows the BER against the optical SNR (OSNR) (dB) for the WDM-PON/HFFSO link with hybrid OOK/M-ary DPPM- and M-PPM using the CL M $=5, l_{f s o}=4000 \mathrm{~m}$, and $\mathrm{D}_{\mathrm{RX}}=25 \mathrm{~mm}$ for ST. The hybrid OOK/M-ary DPPM-PAPM offers about $4 \mathrm{~dB}, 6 \mathrm{~dB}$, and $8 \mathrm{~dB}$ OSNR improvements over 3-DPPM, 4-DPPM, and 5-DPPM of the ST for the WDM. 

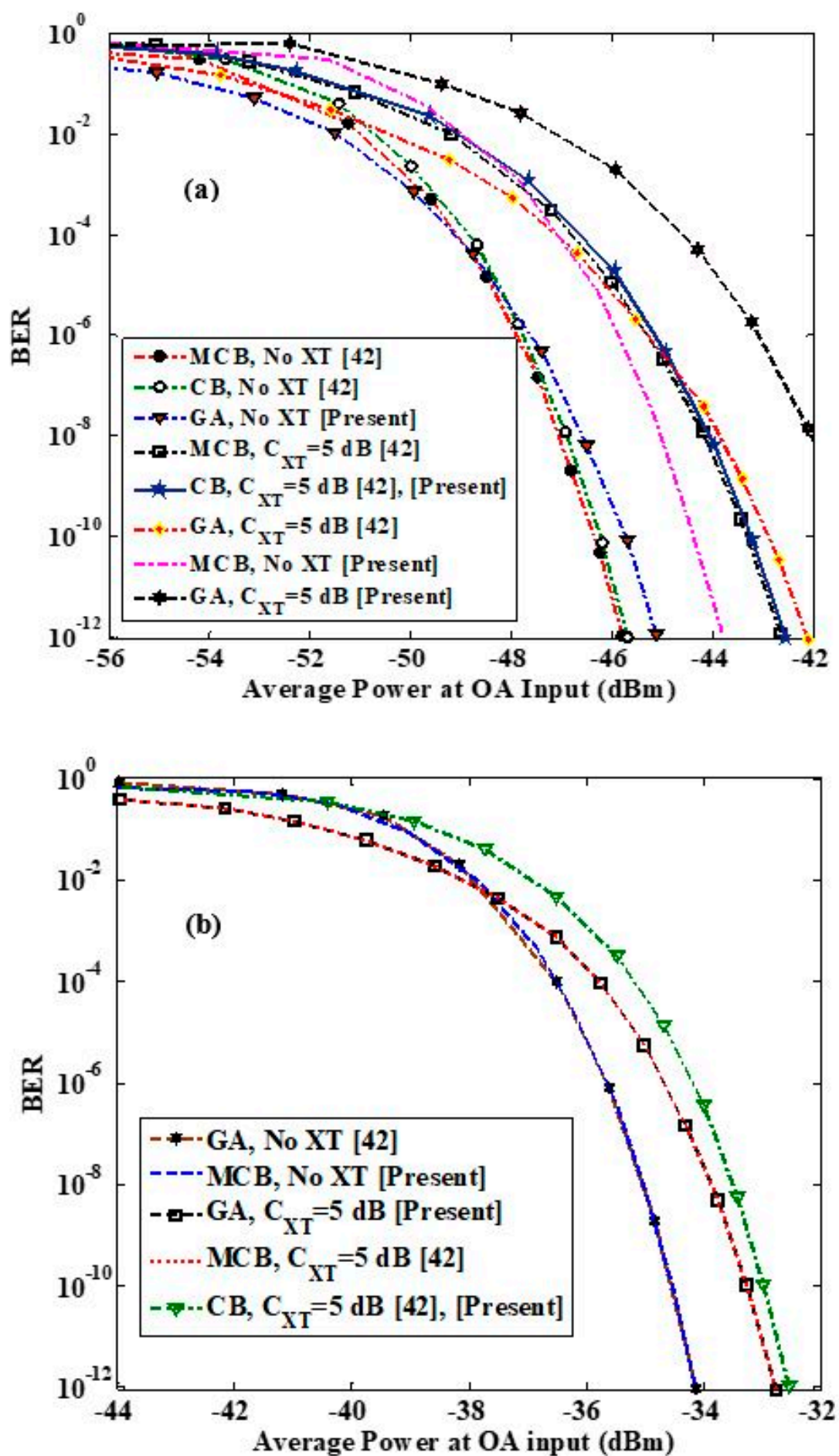

Figure 3. BER against average optical power (AOP) $(\mathrm{dBm})$ using for (a) $\mathrm{G}=27 \mathrm{~dB}$ [42] at $1500 \mathrm{~m}$ and $\mathrm{G}=30 \mathrm{~dB}$ [present work] at $4000 \mathrm{~m}$ and (b) $\mathrm{G}=8 \mathrm{~dB}$ ST is demonstrated in [42] at $1500 \mathrm{~m}$ and [present work] at $4000 \mathrm{~m}$. 

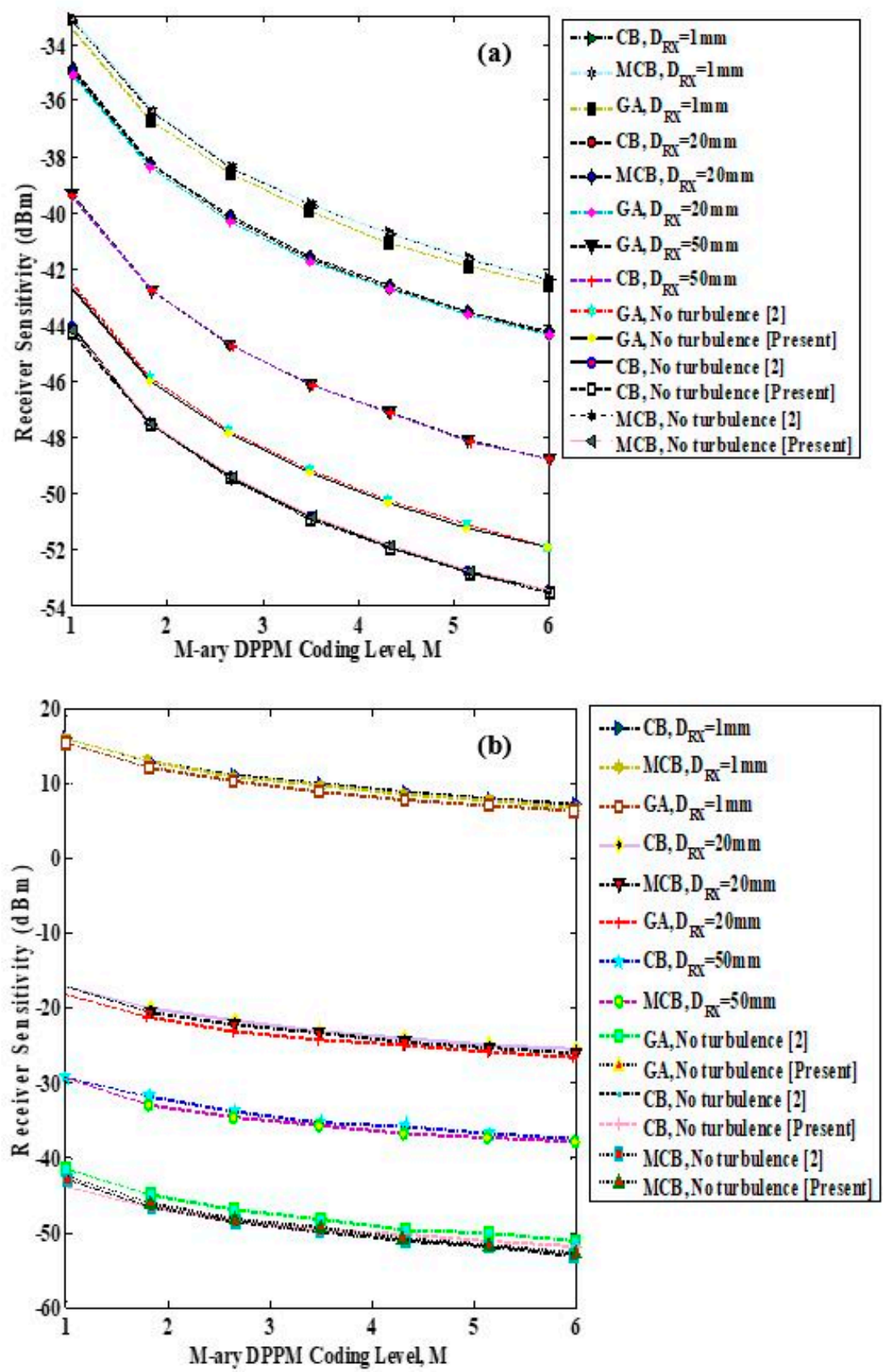

Figure 4. Receiver sensitivity (RS) (dBm) versus M-ary DPPM coding level is presented for the NT with (a) WT condition and (b) ST is demonstrated in [2], [present].

HFFSO optical fiber network, respectively at a target BER of $10^{-12}$. The ST without the hybrid OOK/M-ary modulation format required greater power under the AT effects, ICC, and ASE noise, to achieve the same BER performance than ST with the hybrid OOK/M-ary DPPM scheme as shown in Figure 5. This suggests that the hybrid modulation scheme OOK/M-ary DPPM-PAPM based on WDM-HFFSO communication is favored to ensure greater efficiency and greater performance in our design. The target BER of $10^{-10}$ is achieved for values of $\mathrm{m} \geq 100$, while the BER becomes worse specifically at higher ICC and lower CL for value $\mathrm{m} \leq 100$, as shown in Figure 6. For target BER of $10^{-9}$, the resulting DPPM PP analysis for ICC $\mathrm{M}=2$ is compared to the OOK as shown in Figure 7. The MDPPM-M-PAPM combination produces less PP than the OOK. The M-DPPM-M-PAPM improvement in the PP is improved as the CL number increases from $\mathrm{M}=1$ to 2 and the ICC sources $[5,8,9,46-56]$. The proposed M-ary DPPM-M-PAPM approach increases receiver 
sensitivity in the WDM-M-HFFSO systems compared with OOK-NRZ and improves reliability and produces a lower PP of $0.2-3.0 \mathrm{~dB}$ PP for WT. Without adaptation to reach a BER of $10^{-12}$, the modulation techniques decreased OSNR by $4 \mathrm{~dB}$ as shown in Figure 8 .

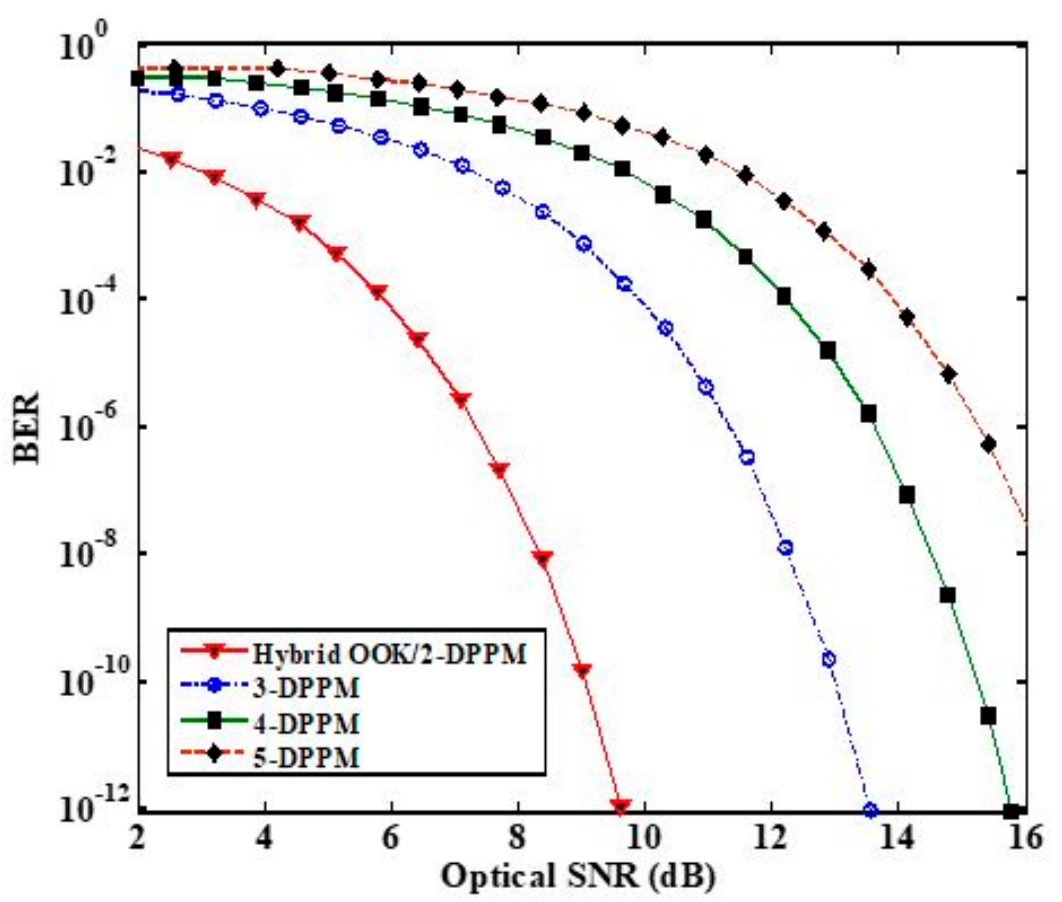

Figure 5. BER vs. OSNR (dB) for the WDM-PON/HFFSO link with hybrid OOK/M-ary DPPM and M-DPPM using $D_{R X}=25 \mathrm{~mm}, \mathrm{M}=5, l_{f s o}=4000 \mathrm{~m}$ for ST.

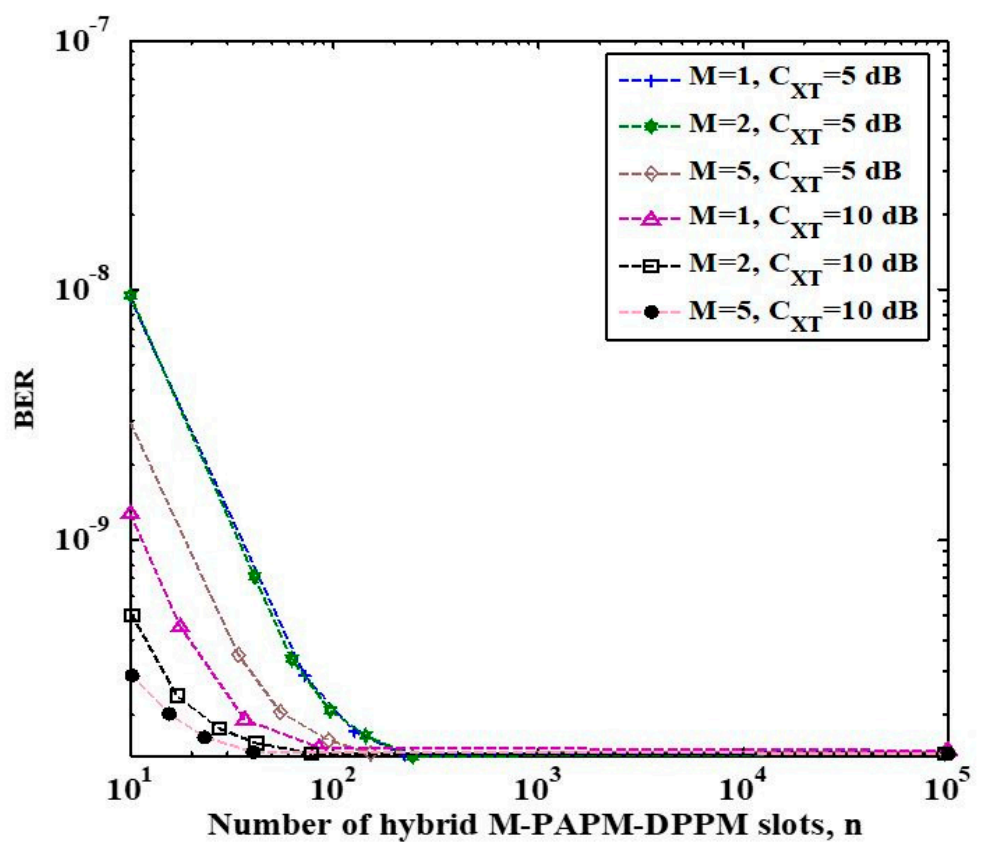

Figure 6. BER vs. the slot numbers (n) for the hybrid M-DPPM-M-PAPM using MCB, G $=30 \mathrm{~dB}$. 


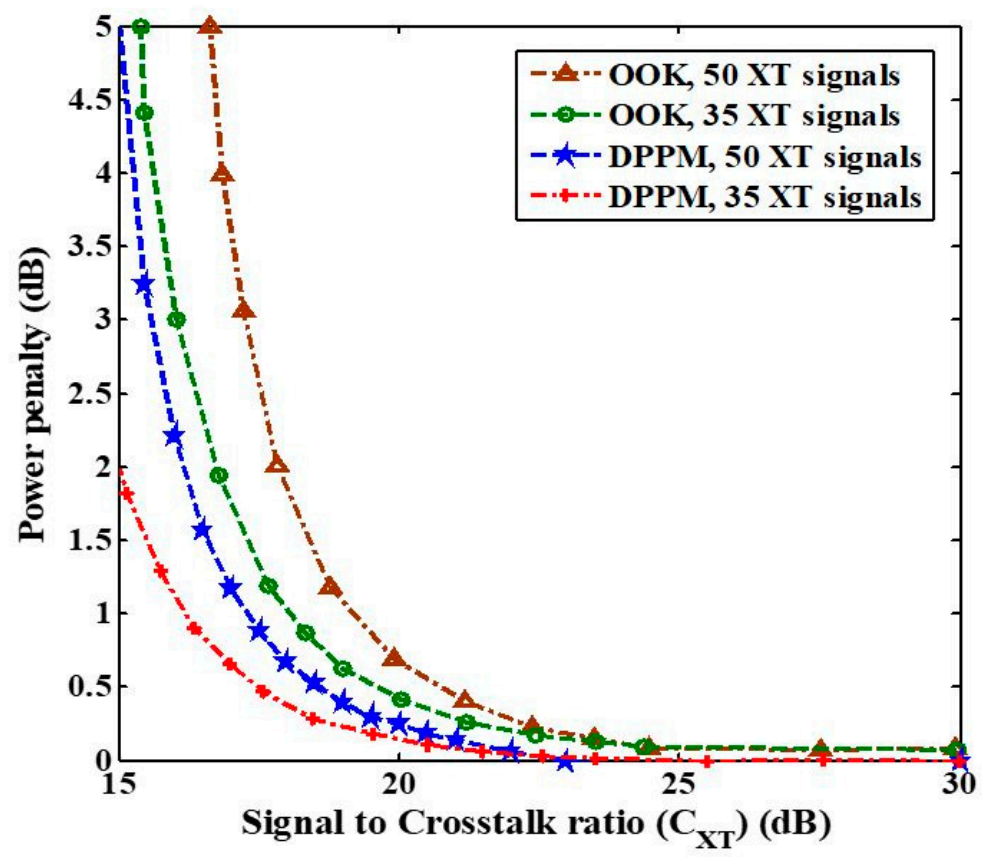

Figure 7. PP vs. $\mathrm{C}_{X \mathrm{~T}}$ for $\mathrm{OOK}$ comparison with DPPM-M-PAPM at $\mathrm{M}=2$ and OOK/M-DPPM-M$\mathrm{PAPM}$ at $\mathrm{BER}=10^{-9}$ for $\mathrm{XT}$ (crosstalk) signals 35 and 50 .

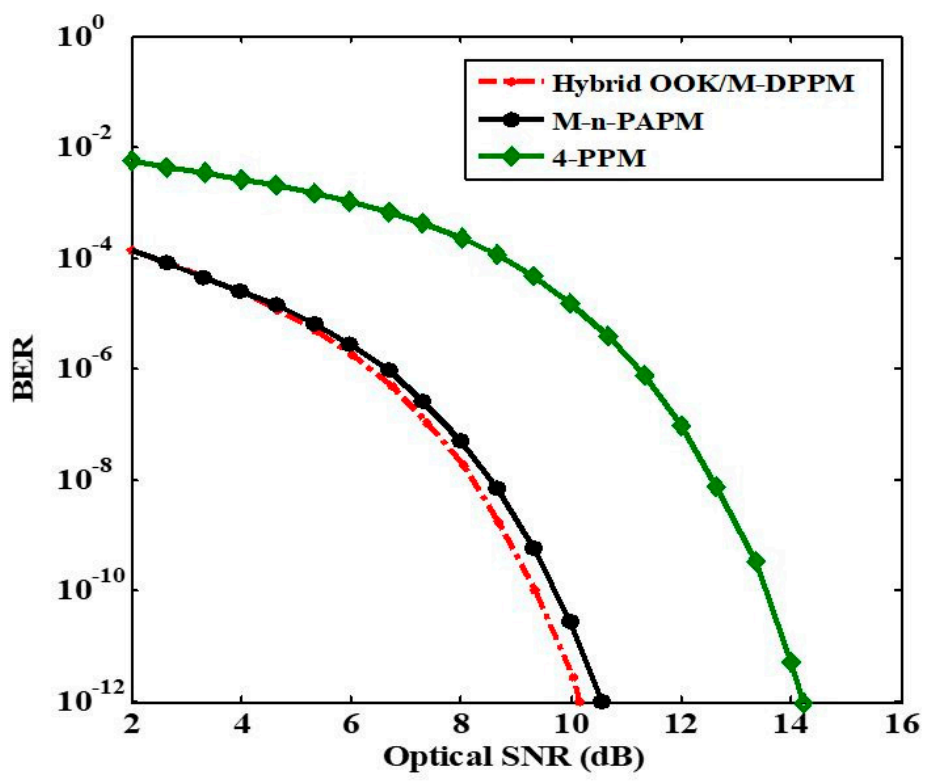

Figure 8. Optical signal-to-noise ratio (OSNR) to BER performance for the hybrid OOK/M-ary DPPM and M-n-PAPM modulation scheme.

Compared to the hybrid OOK/M-ary DPPM, the M-n-PAPM requires $0.3 \mathrm{~dB}$ more power. The results demonstrate that the proposed hybrid OOK/M-DPPM and M-n-PAPM models for the WDM-FSO systems can be improved [54-60]. Table 2 summarizes the proposed modulation schemes of MPPM, M-ary-PAPM, and hybrid M-ary PAPM-MPPM with hybrid $k$-level $n$-pulse where $k^{n}$ (with $\left.k \in\{1,2, \ldots\}\right)[2,8,9,17,42,50]$. Figure 9 shows BER vs. the average RCL power input $(\mathrm{dBm}), \mathrm{D}_{\mathrm{RX}}=25 \mathrm{~mm}$ for $\mathrm{M}$-ary DPPM and OOK for NT and (a) WT (b) MT and (c) ST for M-ary DPPM and G=30 dB, M=5. At the BER target of $10^{-12}$, DPPM provides around 10-11 dB increases in sensitivity compared with the WDM-FSO OOK-NRZ as shown in Figure 9a [2,9,10,17,42-47,56-62]. With a disability in the AT, DPPM's overall sensitivity is reduced to approximately $10 \mathrm{~dB}(\mathrm{WT}), 8 \mathrm{~dB}(\mathrm{MT})$, and $8 \mathrm{~dB}$, respectively (ST). The OOK-NRZ based FSO system offers about 7-9 $\mathrm{dB}$ for the 
DPPM scheme as shown in Figure 9b [2,9]. With AT deficiency, DPPM is reduced to around $7 \mathrm{~dB}(\mathrm{WT}), 8 \mathrm{~dB}(\mathrm{MT})$ and $8 \mathrm{~dB}(\mathrm{ST})[2,9,10,17,42-47]$, respectively as shown in Figure 9c.

Table 2. The proposed M-ary DPPM-M-PAPM based modulation schemes DWDM-FSO optical fiber communication network system $[2,8,9,17,42,50]$.

\begin{tabular}{cccc}
\hline Modulation Scheme & Bits per Symbol & Bandwidth Requirement & Spectral Efficiency \\
\hline MPPM & $\left\lfloor\log _{2}\left(\begin{array}{c}M \\
n\end{array}\right)\right\rfloor$ & $\frac{M R_{b}}{\left\lfloor\log _{2}\left(\begin{array}{c}M \\
n\end{array}\right)\right]}$ & $\frac{\left\lfloor\log _{2}\left(\begin{array}{c}M \\
n\end{array}\right)\right\rfloor}{M}$ \\
\hline M-ary-PAPM & $\left\lfloor\log _{2} k^{n}\left(\begin{array}{c}M \\
n\end{array}\right)\right\rfloor$ & $\frac{M R_{b}}{\left\lfloor\log _{2} \sum_{i=1}^{n}\left(\begin{array}{c}M \\
n\end{array}\right) \mid\right.}$ & $\frac{\left\lfloor\log _{2} k^{n}\left(\begin{array}{c}M \\
n\end{array}\right)\right\rfloor}{M}$ \\
\hline Hybrid M-ary PAPM- & $\left.\log _{2} k^{n} \sum\left(\begin{array}{c}M \\
i\end{array}\right)\right\rfloor=1$ & $\frac{M R_{b}}{\left.\log _{2} k^{n} \sum_{i=1}^{n}\left(\begin{array}{c}M \\
i\end{array}\right)\right]}$ & $\frac{\left.\mid \log _{2} k^{n} \sum_{i=1}^{n}\left(\begin{array}{c}M \\
i\end{array}\right)\right\rfloor}{M}$ \\
\hline
\end{tabular}

M-ary PAPM-DPPM modulation provides about 10-11 dB increases in OOK-NRZ sensitivity for the WDM-FSO optical fiber network system in the absence of turbulence on the target BER with all AA as seen in Figure 10 [48-58]. When the turbulence and ASE noise is present, the OS is reduced to $10 \mathrm{~dB}(\mathrm{WT}), 8 \mathrm{~dB}(\mathrm{MT})$, and $8 \mathrm{~dB}(\mathrm{ST})$ [present] in the sensitivity increase of PAPM DPPM over OOK NRZ [56-62]. It is necessary to ensure and continuously maintain the consistency and accuracy of the simulation models and algorithms with reality. This is accomplished mainly by comparing the simulation behavior to the simulation and experimental results achieved in $[2,5,8,9,15,42,50]$. Also, in our research several (successful) comparisons were done, sets of the previous research and comparing them with the results of models. Tables 1,3 and 4 show the system parameters used for calculations $[2,5,8,9,15,42,50]$ and [Proposed work]. The simulation results reveal that the BER's WDM/PAPM-DPPM is better than that of OOK-NRZ by approximately $10 \mathrm{~dB}-11 \mathrm{~dB}$ of $10^{-12}$. Table 3 provides the performance comparison of the proposed hybrid M-ary-PAPM M-DPPM-based DWDM FSO optical fiber network link with contemporary literature for the references $[2,5,8,9,15,42]$. The numerical results show a highly efficient M-ary-PAPM M-DPPM-based DWDM FSO has been designed by incorporating a DWDM-PON optical fiber network. The results of the numerical investigation demonstrate that the proposed link performance improves on increasing the increased receiver sensitivity, capacity, and efficiency under the atmospheric turbulence effects. We illustrate a comparative investigation of the proposed M-ary DPPM-M-PAPMbased DWDM-FSO optical fiber communication systems performance with contemporary literature and show that the proposed link performs better for maximum range, efficiency, and channel capacity. We reduce the ASE noise, AT channels, and (ICC for the DWDM-FSO optical fiber communication systems. Table 4 shows the performance comparison of the proposed M-ary DPPM-M-PAPM based-DWDM-FSO optical fiber link with reference [50]. The proposed hybrid M-ary-PAPM M-DPPM provides an improvement of 4-8 $\mathrm{dB}$ at a BER of $10^{-12}$ (OSNR) [proposed work] while in Ref. [50] it is 1 and $2 \mathrm{~dB}$ at a BER of $10^{-6}$. 

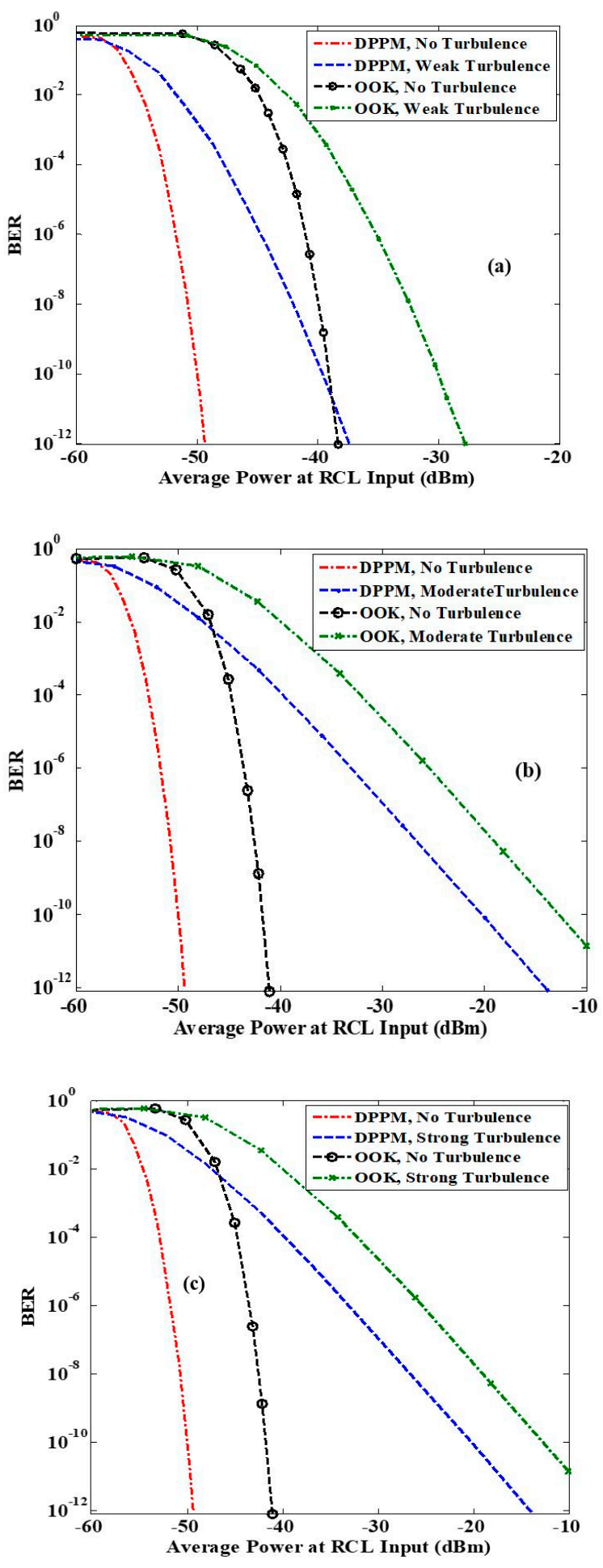

Figure 9. BER vs. AOP at RCL input (dBm) for M-ary DPPM and OOK using $D_{R X}=25 \mathrm{~mm}, \mathrm{G}=30 \mathrm{~dB}$, $\mathrm{M}=5$, and $l_{f s o}=4000 \mathrm{~m}$ for NT with (a) WT, (b) MT, and (c) ST. 


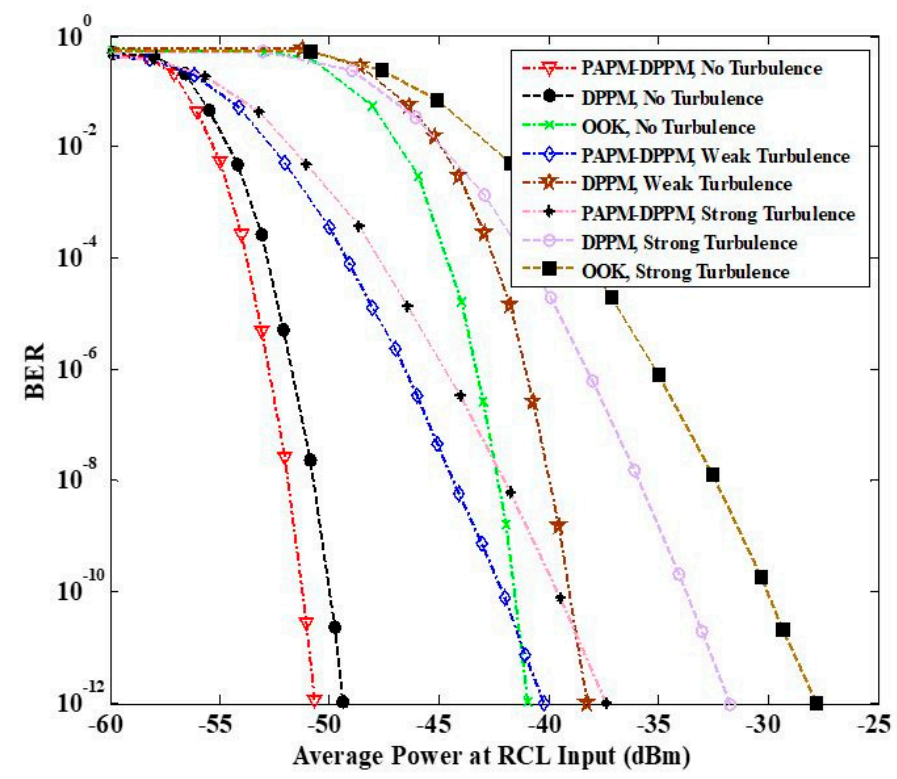

Figure 10. BER vs. AOP at RCL input (dBm) for DPPM and OOK for no turbulence and WT with all apertures averaging (AA).

Table 3. Performance comparison of the proposed M-ary DPPM-M-PAPM based-DWDM-FSO optical fiber link with contemporary literature.

\begin{tabular}{|c|c|c|c|c|c|c|c|}
\hline & Ref. [2] & Ref. [5] & Ref. [8] & Ref. [9] & Ref. [15] & Ref. [42] & [Proposed Work] \\
\hline Technique used & $\begin{array}{l}\text { DPPM-FSO } \\
\text { link }\end{array}$ & $\begin{array}{l}\text { WDM-FSO } \\
\text { hybrid } \\
\text { fiber-based } \\
\text { DPPM }\end{array}$ & $\begin{array}{l}\text { DPPM- based } \\
\text { DWDM-FSO } \\
\text { system }\end{array}$ & $\begin{array}{c}\text { M-ary } \\
\text { PPM-based } \\
\text { WDM -FSO } \\
\text { system }\end{array}$ & $\begin{array}{c}\text { WDM-FSO } \\
\text { network-based } \\
\text { DPPM } \\
\text { modulation }\end{array}$ & $\begin{array}{c}\text { DPPM-based } \\
\text { WDM-FSO } \\
\text { communication } \\
\text { system }\end{array}$ & $\begin{array}{c}\text { hybrid M-ary-PAPM } \\
\text { M-DPPM-based DWDM FSO } \\
\text { optical fiber network }\end{array}$ \\
\hline Data rate & $2.5 \mathrm{Gbps}$ & $2.5 \mathrm{Gbps}$ & $2.5 \mathrm{Gbps}$ & $2.5 \mathrm{Gbps}$ & $2.5 \mathrm{Gbps}$ & $2.5 \mathrm{Gbps}$ & $2.5 \mathrm{Gbps}$ \\
\hline Net capacity & $2.5 \mathrm{Gbit} / \mathrm{s}$ & $5 \mathrm{Gbit} / \mathrm{s}$ & $20 \mathrm{Gbit} / \mathrm{s}$ & $20 \mathrm{Gbit} / \mathrm{s}$ & $5 \mathrm{Gbit} / \mathrm{s}$ & $5 \mathrm{Gbit} / \mathrm{s}$ & $20 \mathrm{Gbit} / \mathrm{s}$ \\
\hline $\begin{array}{l}\text { Maximum link } \\
\text { range reported }\end{array}$ & $1500 \mathrm{~m}$ & $2000 \mathrm{~m}$ & $4000 \mathrm{~m}$ & $2500 \mathrm{~m}$ & $2000 \mathrm{~m}$ & $2000 \mathrm{~m}$ & $4000 \mathrm{~m}$ \\
\hline $\begin{array}{l}\text { Quantum } \\
\text { efficiency }\end{array}$ & 0.75 & 0.8 & 1 & 1 & 0.8 & 0.9 & 1 \\
\hline $\begin{array}{c}\text { No. of channels } \\
\text { Target BER }\end{array}$ & $\begin{array}{c}1 \\
10^{-12}\end{array}$ & $\begin{array}{c}2 \\
10^{-12}\end{array}$ & $\begin{array}{c}8 \\
10^{-12}\end{array}$ & $\begin{array}{c}8 \\
10^{-12}\end{array}$ & $\begin{array}{c}2 \\
10^{-12}\end{array}$ & $\begin{array}{c}2 \\
10^{-12}\end{array}$ & $\begin{array}{c}8 \\
10^{-12}\end{array}$ \\
\hline
\end{tabular}

Table 4. Performance comparison of proposed M-ary DPPM-M-PAPM based-DWDM-FSO optical fiber link with reference [50].

\begin{tabular}{ccc}
\hline Modulation scheme technique & $\begin{array}{c}\text { Ref. [50] } \\
\text { hybrid MPAPM technique } \\
\text { deep space optical link }\end{array}$ & $\begin{array}{c}\text { hybrid M-ary-PAPM } \\
\text { [PPM-based DWDM FSO } \\
\text { optical fiber network }\end{array}$ \\
\hline OSNR improved & $1 \mathrm{~dB}$ and 2 dB & $4-8 \mathrm{~dB}$ \\
\hline Target BER & $10^{-6}$ & $10^{-12}$ \\
\hline Optical pulses per frame for $\boldsymbol{M}$ & 16 & 16 \\
\hline
\end{tabular}

\section{Conclusions}

In this work, we studied and enhanced the HFFSO optical fiber communication network system using the hybrid modulation techniques of OOK/M-ary DPPM-M-PAPM, based on the DWDM-PON network. ICC analyses for DWDM-DPPM systems are given for the GA, CB, and MCB. Also, we consider using hybrid OOK/M-ary DPPM-M-PAPM modulation techniques to increase spectral efficiency and incorporate adaptive optics to mitigate the crosstalk interferences in the DWDM-PON/HFFSO scenarios for improved reliability. The BER performances are then theoretically analyzed. In the presence of atmo- 
spheric turbulences, the OOK/M-ary hybrid DPPM modulation scheme is an excellent way to increase DWDM-PON/HFFSO efficiency. Furthermore, the results obtained show that the ICC interferences could be effectively suppressed thanks to the M-ary DPPM-M-PAPM modulation and that the proposed system could achieve superior BER performance. We investigate the impact of the turbulence effect on the proposed system performance based on OOK-M-ary-DPPM modulation as a function of $\mathrm{M}$ and other atmospheric parameters. The proposed design of the M-ary DPPM-M-PAPM can improve the power penalty over OOK-NRZ and enhances performance efficiency. The proposed M-ary DPPM-M-PAPM architecture can enhance the receiver sensitivity and reliability over OOK-NRZ.

Author Contributions: M.R.H. made substantial contributions to the design, analysis, characterization, conceptualization, methodology, software, data curation, writing-original draft, formal analysis, writing, visualization, investigation, discussed the results, reviewed, approved the article, validation and provided the revised the article critically for important intellectual content and gave final approval of the version to be submitted. B.B.Y. and M.A.A. participated in the conception and critical revision of the article for important intellectual content, supervision, discussed the results, reviewed and approved the article, project administration, data curation, and writing-review \& editing and revised it critically for important intellectual content. All authors have read and agreed to the published version of the manuscript.

Funding: This research received no external funding.

Data Availability Statement: The data that support the findings of this study are available within this article.

Conflicts of Interest: The authors declare that there is no conflict of interest regarding the manuscript.

\section{References}

1. Phillips, A.; Cryan, R.; Senior, J. An optically preamplified intersatellite PPM receiver employing maximum likelihood detection. IEEE Photon-Technol. Lett. 1996, 8, 691-693. [CrossRef]

2. Aladeloba, A.; Phillips, A.; Woolfson, M. Performance evaluation of optically preamplified digital pulse position modulation turbulent free-space optical communication systems. IET Optoelectron. 2012, 6, 66-74. [CrossRef]

3. Ohtsuki, T. Performance analysis of indoor infrared wireless systems using PPM CDMA. Electron. Commun. Jpn. Part I Commun. 2002, 85, 1-10. [CrossRef]

4. Leeson, M. Pulse position modulation for spectrum-sliced transmission. IEEE Photon-Technol. Lett. 2004, 16, 1191-1193. [CrossRef]

5. Mbah, A.M.; Walker, J.G.; Phillips, A.J. Performance evaluation of turbulence-accentuated interchannel crosstalk for hybrid fibre and free-space optical wavelength-division-multiplexing systems using digital pulse-position modulation. IET Optoelectron. 2016, 10, 11-20. [CrossRef]

6. Garrett, I. Pulse-position modulation for transmission over optical fibers with direct or heterodyne detection. IEEE Trans. Commun. 1983, 31, 518-527. [CrossRef]

7. Phillips, A.; Cryan, R.; Senior, J. Optically preamplified pulse-position modulation for fibre-optic communication systems. IEE Proc.-Optoelectron. 1996, 143, 153-159. [CrossRef]

8. Elsayed, E.E.; Yousif, B.B.; Alzalabani, M.M. Performance enhancement of the power penalty in DWDM FSO communication using DPPM and OOK modulation. Opt. Quantum Electron. 2018, 50, 282. [CrossRef]

9. Elsayed, E.E.; Yousif, B.B. Performance enhancement of M-ary pulse-position modulation for a wavelength division multiplexing free-space optical systems impaired by interchannel crosstalk, pointing error, and ASE noise. Opt. Commun. 2020, 475, 126219. [CrossRef]

10. Elsayed, E.E.; Yousif, B.B. Performance enhancement of the average spectral efficiency using an aperture averaging and spatialcoherence diversity based on the modified-PPM modulation for MISO FSO links. Opt. Commun. 2020, 463, 125463. [CrossRef]

11. De Andrade, M.; Kramer, G.; Wosinska, L.; Chen, J.; Sallent, S.; Mukherjee, B. Evaluating strategies for evolution of passive optical networks. IEEE Commun. Mag. 2011, 49, 176-184. [CrossRef]

12. Kramer, G.; Pesavento, G. Ethernet passive optical network (EPON): Building a next-generation optical access network. IEEE Commun. Mag. 2002, 40, 66-73. [CrossRef]

13. Kim, B.; Kim, B.-W. WDM-PON development and deployment as a present optical access solution. In Proceedings of the Optical Fiber Communication Conference, San Diego, CA, USA, 22-26 March 2009.

14. Wang, K.; Nirmalathas, A.; Lim, C.; Skafidas, E. $4 \times 12.5$ Gb/s WDM optical wireless communication system for indoor applications. J. Light. Technol. 2011, 29, 1988-1996. [CrossRef]

15. Aladeloba, A.O.; Woolfson, M.S.; Phillips, A.J. WDM FSO network with turbulence-accentuated interchannel crosstalk. J. Opt. Commun. Netw. 2013, 5, 641-651. [CrossRef] 
16. Chang, G.-K.; Chowdhury, A.; Jia, Z.; Chien, H.-C.; Huang, M.-F.; Yu, J.; Ellinas, G. Key technologies of WDM-PON for future converged optical broadband access networks. J. Opt. Commun. Netw. 2009, 1, C35-C50. [CrossRef]

17. Available online: http://eprints.nottingham.ac.uk/13304/1/AladelobaAbisayoThesis.pdf (accessed on 10 October 2021).

18. Ciaramella, E.; Arimoto, Y.; Contestabile, G.; Presi, M.; D’Errico, A.; Guarino, V.; Matsumoto, M. 1.28 terabit/s (32 × 40 Gbit/s) WDM transmission system for free space optical communications. IEEE J. Sel. Areas Commun. 2009, 27, 1639-1645. [CrossRef]

19. Forbes, M.; Gourlay, J.; Desmulliez, M. Optically interconnected electronic chips: A tutorial and review of the technology. Electron. Commun. Eng. J. 2001, 13, 221-232. [CrossRef]

20. Ansari, N.; Zhang, J. Media Access Control and Resource Allocation: For Next Generation Passive Optical Networks; Springer Science \& Business Media: Berlin/Heidelberg, Germany, 2013.

21. Zuo, T.; Phillips, A. Performance of burst-mode receivers for optical digital pulse position modulation in passive optical network application. IET Optoelectron. 2009, 3, 123-130. [CrossRef]

22. Yousif, B.B.; Elsayed, E.E. Performance enhancement of an orbital-angular-momentum-multiplexed free-space optical link under atmospheric turbulence effects using spatial-mode multiplexing and hybrid diversity based on adaptive MIMO equalization. IEEE Access 2019, 7, 84401-84412. [CrossRef]

23. Yamamoto, Y. Noise and error rate performance of semiconductor laser amplifiers in PCM-IM optical transmission systems. IEEE J. Quantum Electron. 1980, 16, 1073-1081. [CrossRef]

24. Ribeiro, L.; da Rocha, J.; Pinto, O.; da Rocha, J.F.; Pinto, J. Performance evaluation of EDFA preamplified receivers taking into account intersymbol interference. J. Light. Technol. 1995, 13, 225-232. [CrossRef]

25. O'Reilly, J.; da Rocha, J.F. Improved error probability evaluation methods for direct detection optical communication systems. IEEE Trans. Inf. Theory 1987, 33, 839-848. [CrossRef]

26. Al-Orainy, A.; O'Reilly, J. Error probability bounds and approximations for the influence of crosstalk on wavelength division multiplexed systems. IEE Proc. J Optoelectron. 1990, 137, 379-384. [CrossRef]

27. Personick, S.D. Applications for quantum amplifiers in simple digital optical communication systems. Bell Syst. Tech. J. 1973, 52, 117-133. [CrossRef]

28. Ma, R.; Zuo, T.; Phillips, A.; Sujecki, S. Improved performance evaluation for DC-coupled burst mode reception in the presence of amplified spontaneous emission noise and interchannel crosstalk. IET Optoelectron. 2010, 4, 121-132. [CrossRef]

29. Elsayed, E.E.; Yousif, B.B. Performance enhancement of hybrid diversity for M-ary modified pulse-position modulation and spatial modulation of MIMO-FSO systems under the atmospheric turbulence effects with geometric spreading. Opt. Quantum Electron. 2020, 52, 1-18. [CrossRef]

30. Andrews, L.C.; Phillips, R.L.; Young, C.Y. Laser Beam Scintillation with Applications; SPIE: Bellingham, WA, USA, 2001. [CrossRef]

31. Trinh, P.V.; Dang, N.T.; Thang, T.C.; Pham, A. Performance of all-optical amplify-and-forward WDM/FSO relaying systems over atmospheric dispersive turbulence channels. IEICE Trans. Commun. 2016, 99, 1255-1264. [CrossRef]

32. Majumdar, A.K. Free-space laser communication performance in the atmospheric channel. J. Opt. Fiber Commun. Rep. 2005, 2, 345-396. [CrossRef]

33. Khalighi, M.; Schwartz, N.; Aitamer, N.; Bourennane, S. Fading reduction by aperture averaging and spatial diversity in optical wireless systems. J. Opt. Commun. Netw. 2009, 1, 580-593. [CrossRef]

34. Al-Habash, M.A. Mathematical model for the irradiance probability density function of a laser beam propagating through turbulent media. Opt. Eng. 2001, 40, 1554. [CrossRef]

35. Popoola, W.O.; Ghassemlooy, Z. BPSK subcarrier intensity modulated free-space optical communications in atmospheric turbulence. J. Light. Technol. 2009, 27, 967-973. [CrossRef]

36. Rajiv Ramaswami, K.N.S. Optical Networks a Practical Perspective. 2010. Available online: http://www.cesarkallas.net/ arquivos / faculdade-pos/TP319-redes-opticas/Optical-Networks-3nd.pdf (accessed on 10 October 2021).

37. Maru, K.; Mizumoto, T.; Uetsuka, H. Demonstration of flat-passband multi/demultiplexer using multi-input arrayed waveguide grating combined with cascaded mach-zehnder interferometers. J. Light. Technol. 2007, 25, 2187-2197. [CrossRef]

38. Hirano, A.; Miyamoto, Y.; Kuwahara, S. Performances of CSRZ-DPSK and RZ-DPSK in 43-Gbit/s/ch DWDM G.652 single-modefiber transmission. J. Lightwave Technol. 2003, 86, 454-456. [CrossRef]

39. Yu, C.X.; Neilson, D.T. Diffraction-grating-based (de)multiplexer using image plane transformations. IEEE J. Sel. Top. Quantum Electron. 2002, 8, 1194-1201. [CrossRef]

40. Henry, P.S. Error-rate performance of optical amplifiers. In Proceedings of the Optical Fiber Communication Conference, Houston, TX, USA, 6 February 1989.

41. Elsayed, E.E.; Yousif, B.B. Performance evaluation and enhancement of the modified OOK based IM/DD techniques for hybrid fiber/FSO communication over WDM-PON systems. Opt. Quantum Electron. 2020, 52, 1-27. [CrossRef]

42. Mbah, A.M.; Walker, J.G.; Phillips, A.J. Performance evaluation of digital pulse position modulation for wavelength division multiplexing FSO systems impaired by interchannel crosstalk. IET Optoelectron. 2014, 8, 245-255. [CrossRef]

43. Yousif, B.B.; Elsayed, E.E.; Alzalabani, M.M. Atmospheric turbulence mitigation using spatial mode multiplexing and modified pulse position modulation in hybrid RF/FSO orbital-angular-momentum multiplexed based on MIMO wireless communications system. Opt. Commun. 2019, 436, 197-208. [CrossRef]

44. Mbah, A.M.; Walker, J.G.; Phillips, A.J. Outage probability of WDM free-space optical systems affected by turbulence-accentuated interchannel crosstalk. IET Optoelectron. 2017, 11, 91-97. [CrossRef] 
45. Aladeloba, A.; Phillips, A.; Woolfson, M. Improved bit error rate evaluation for optically pre-amplified free-space optical communication systems in turbulent atmosphere. IET Optoelectron. 2012, 6, 26-33. [CrossRef]

46. Aladeloba, A.O.; Phillips, A.J.; Woolfson, M.S. DPPM FSO communication systems impaired by turbulence, pointing error and ASE noise. In Proceedings of the 14th International Conference on Transparent Optical Networks (ICTON), Coventry, UK, 2-5 July 2012; pp. 1-4. [CrossRef]

47. Mukherjee, B. WDM optical communication networks: Progress and challenges. IEEE J. Sel. Areas Commun. 2000, 18, 1810-1824. [CrossRef]

48. Mallick, K.; Mandal, P.; Mandal, G.C.; Mukherjee, R.; Das, B.; Patra, A.S. Hybrid MMW-over fiber/OFDM-FSO transmission system based on doublet lens scheme and POLMUX technique. Opt. Fiber Technol. 2019, 52, 101942. [CrossRef]

49. Mallick, K.; Mandal, P.; Mukherjee, R.; Mandal, G.C.; Das, B.; Patra, A.S. Generation of 40 GHz/80 GHz OFDM based MMW source and the OFDM-FSO transport system based on special fine tracking technology. Opt. Fiber Technol. 2020, 54, 102130. [CrossRef]

50. Idris, S.; Selmy, H.; Lopes, W.T.A. Performance analysis of hybrid MPAPM technique for deep-space optical communications. IET Commun. 2021, 15, 1700-1709. [CrossRef]

51. Magidi, S.; Jabeena, A. Analysis of multi-pulse position modulation free space optical communication system employing wavelength and time diversity over Malaga turbulence channel. Sci. Afr. 2021, 12, e00777. [CrossRef]

52. Alipour, A.; Farmani, A.; Mir, A. Analysis of optical power budget in DWDM-FSO link under outdoor atmospheric channel model. Opt. Quantum Electron. 2021, 53, 1-15. [CrossRef]

53. Ran, H.; Zhang, J.; Pan, G.; Xie, Y. Outage probability of wireless-powered multi-relaying MIMO FSO-RF systems. Opt. Commun. 2021, 498, 127260. [CrossRef]

54. Zhang, T.; Wang, P.; Liu, T.; Jia, C.; Pang, W.-N.; Wang, W. Performance analysis of multi-hop parallel FSO system over double generalized gamma distribution considering two transmission beams. Optoelectron. Lett. 2021, 17, 215-220. [CrossRef]

55. Willner, A.E.; Zhao, Z.; Liu, C.; Zhang, R.; Song, H.; Pang, K.; Manukyan, K.; Song, H.; Su, X.; Xie, G.; et al. Perspectives on advances in high-capacity, free-space communications using multiplexing of orbital-angular-momentum beams. APL Photonics 2021, 6, 030901. [CrossRef]

56. Sharma, K.; Grewal, S.K. Performance assessment of hybrid PPM-BPSK-SIM based FSO communication system using time and wavelength diversity under variant atmospheric turbulence. Opt. Quantum Electron. 2020, 52, 1-25. [CrossRef]

57. Singh, M.; Malhotra, J. Performance comparison of M-QAM and DQPSK modulation schemes in a $2 \times 20 \mathrm{Gbit} / \mathrm{s}-40 \mathrm{GHz}$ hybrid MDM-OFDM-based radio over FSO transmission system. Photon.-Netw. Commun. 2019, 38, 378-389. [CrossRef]

58. Malik, S.; Sahu, P.K. Performance analysis of free space optical communication system using different modulation schemes over weak to strong atmospheric turbulence channels. Lect. Notes Electr. Eng. 2019, 546, 387-399. [CrossRef]

59. Srivastava, V.; Mandloi, A.; Soni, G.G. Outage probability and average BER estimation of FSO system employing wavelength diversity. Opt. Quantum Electron. 2019, 51, 229. [CrossRef]

60. Mukherjee, R.; Mallick, K.; Kuiri, B.; Santra, S.; Dutta, B.; Mandal, P.; Patra, A.S. PAM-4 based long-range free-space-optics communication system with self injection locked QD-LD and RS codec. Opt. Commun. 2020, 476, 126304. [CrossRef]

61. Mukherjee, R.; Mallick, K.; Mandal, P.; Dutta, B.; Kuiri, B.; Patra, A.S. Bidirectional hybrid OFDM based free-space/wireless-overfiber transport system. Opt. Quantum Electron. 2020, 52, 1-12. [CrossRef]

62. Saxena, P.; Mathur, A.; Bhatnagar, M.R. BER performance of an optically pre-amplified FSO system under turbulence and pointing errors with ASE noise. J. Opt. Commun. Netw. 2017, 9, 498-510. [CrossRef] 